\title{
PENGARUH SERBUK U-Mo HASIL PROSES MEKANIK DAN HYDRIDE - DEHYDRIDE - GRINDING MILL TERHADAP KUALITAS PELAT ELEMEN BAKAR U-Mo/AI
}

\author{
Supardjo, Agoeng Kadarjono, Boybul \\ Pusat Teknologi Bahan Bakar Nuklir - BATAN \\ Kawasan Puspiptek, Serpong, Tangerang Selatan, 15314 \\ e-mail: suparjo@batan.go.id \\ (Naskah diterima : 30-04-2015, Naskah direvisi: 05-05-2015, Naskah disetujui: 13-05-2015)
}

\begin{abstract}
ABSTRAK
PENGARUH SERBUK U-MO HASIL PROSES MEKANIK DAN HYDRIDE - DEHYDRIDE GRINDING MILL TERHADAP KUALITAS PELAT ELEMEN BAKAR U-Mo/AI. Penelitian bahan bakar U-7Mo/Al tipe pelat dilakukan dalam rangka pengembangan bahan bakar $\mathrm{U}_{3} \mathrm{Si}_{2} / \mathrm{Al}$ untuk mendapatkan bahan bakar baru yang memiliki densitas uranium lebih tinggi, stabil selama digunakan sebagai bahan bakar di dalam reaktor dan mudah dilakukan proses olah ulangnya. Lingkup penelitian meliputi pembuatan: paduan U-7Mo dengan teknik peleburan, pembuatan serbuk U-7Mo dengan dikikir dan hydride - dehydride - grinding mill, IEB U-7Mo/Al dengan teknik kompaksi pada tekanan 20 bar, dan PEB U-7Mo/Al dengan teknik pengerolan panas pada temperatur $425^{\circ} \mathrm{C}$. Paduan U-7Mo hasil proses peleburan cukup homogen, berat jenis $16,34 \mathrm{~g} / \mathrm{cm}^{3}$ dan bersifat ulet, kemudian dibuat menjadi serbuk dengan cara dikikir dan hydride - dehydride grinding mill. Serbuk U-7Mo hasil proses kikir berbentuk pipih, kontaminan Fe cukup tinggi, sedangkan serbuk hasil proses hydride - dehydride - grinding mill, cenderung equiaxial dengan kontaminan yang rendah. Kedua jenis serbuk U-7Mo tersebut digunakan sebagai bahan baku pembuatan IEB U-7Mo/AI dan PEB U-7Mo/Al dengan densitas uranium $7 \mathrm{gU} / \mathrm{cm}^{3}$ dan diperoleh produk dengan kualitas yang hampir sama. Hasil uji IEB U-7Mo/AI berukuran $25 \times 15 \times 3,15^{ \pm 0,05}$ $\mathrm{mm}$, tidak terdapat cacat/retak, distribusi U-7Mo di dalam matriks cukup homogen dan tidak terdapat pengelompokan/aglomerasi U-7Mo yang berdimensi $>1 \mathrm{~mm}$. PEB U-7Mo/Al hasil pengerolan dengan tebal akhir $1,45 \mathrm{~mm}$, memiliki ketebalan meat rerata $0,60 \mathrm{~mm}$ dan tebal kelongsong 0,4 mm dan terdapat 1 titik pengukuran kelongsong dengan ketebalan 0,15 mm. Dengan membandingkan penggunaan kedua jenis serbuk U-7Mo tersebut, IEB U-7Mo/AI dan PEB U-7Mo/Al yang dihasilkan memiliki kualitas hampir sama. Namun demikian penggunaan serbuk $\mathrm{U}$ - 7Mo hasil proses hydride - dehydride - grinding mill lebih baik karena proses pengerjaannya lebih cepat dan impuritas dalam serbuk dapat diperkecil.
\end{abstract}

Kata kunci: paduan U-7Mo, serbuk U-7Mo inti elemen bakar U-7Mo/Al, pelat elemen bakar $\mathrm{U}-7 \mathrm{Mo} / \mathrm{Al}$, bahan bakar dispersi.

\section{ABSTRACT}

INFLUENCE OF U-MO POWDER BY MECHANICAL AND HYDRIDE - DEHYDRIDE - GRINDING MILL PROCESS RESULT OF U-MO / AI FUEL PLATE QUALITY. Research of U-7Mo/Al fuel type plate is done in order to develop $\mathrm{U}_{3} \mathrm{Si}_{2} / \mathrm{Al}$ fuel to get a new fuel that has a higher uranium density, stable for use as fuel in the reactor and is easily done if the reprocessed. The scope of the research includes manufacture: U-7Mo alloy with smelting techniques, pulverizing U-7Mo to be filed and hydridedehydride-grinding mill, U-7Mo/Al fuel core with the technique of compacting at a pressure of 20 
bar, and U-7Mo/Al fuel plate with technique of hot rolling at a temperature of $425^{\circ} \mathrm{C}$. The $U-7 M o$ alloy results smelting process quite homogeneous, the density of $16.34 \mathrm{~g} / \mathrm{cm}^{3}$ and is tenacious, then made powder by means of filed and hydride-dehydride-grinding mill. The U-7Mo powder shaped flat results miserly process, contaminants $\mathrm{Fe}$ is high enough, whereas powder process results hydride- dehydride-grinding mill, tend equiaxial with low contaminants. The second type of U-7Mo powder is used as a raw material for making U-7Mo/Al fuel core and U-7Mo/Al fuel plate with $7 \mathrm{gU} / \mathrm{cm}^{3}$ uranium density and obtained product with almost the same quality. The U-7Mo/AI fuel core test results measuring $25 \times 15 \times 3.15^{ \pm 0.05} \mathrm{~mm}$, there is no defect/crack, U-7Mo distribution in the matrix is quite homogeneous and there is no grouping/agglomeration U-7Mo dimension $>1$ $\mathrm{mm}$. The U-7Mo/Al fuel plate outcome rolling with a final thickness of $1.45 \mathrm{~mm}$, has a thickness of $0.60 \mathrm{~mm}$ and a mean meat cladding thickness of $0.4 \mathrm{~mm}$, and there is one point of measurement of cladding with a thickness of $0.15 \mathrm{~mm}$. By comparing the use of both types of U-7Mo powders the U-7Mo/Al fuel core and U-7Mo/Al fuel plate produced has almost the same quality. However, the use of U-7Mo powder results hydride-dehydride-grinding mill process is better because the workmanship is faster and impurities in the powders can be minimized.

Keywords: U-7Mo alloy, U-7Mo powder, U-7Mo/Al fuel core, U-7Mo/Al fuel plates, dispersion fuel.

\section{PENDAHULUAN}

Bahan bakar reaktor riset dengan uranium pengayaan rendah $<20 \%{ }^{235} \mathrm{U}$ dalam bentuk dispersi dan monolitik sedang dikembangkan oleh periset dunia dalam rangka mendapatkan bahan bakar baru yang memiliki densitas uranium tinggi, mudah difabrikasi, stabil selama digunakan sebagai bahan bakar di dalam reaktor dan olah ulang bahan bakar mudah dilakukan. Material yang mempunyai prospek untuk keperluan tersebut adalah bahan bakar dengan struktur kristal $\mathrm{\gamma}-\mathrm{U}$, dimana stabilitas di dalam reaktor dapat dipertahankan.

Paduan uranium yang memiliki kecenderungan membentuk fasa $\mathrm{Y}-\mathrm{U}$ antara lain: U-Cr, U-Mo, U-Nb, U-Re, U-Ru, U-Ti, $\mathrm{U}-\mathrm{V}$ dan $\mathrm{U}-\mathrm{Zr}^{[1]}$. Diantara paduan tersebut yang memiliki rentang fasa $\gamma-U$ relatif luas adalah U-Mo sehingga paduan tersebut dipilih sebagai kandidat bahan bakar di masa datang. Pemilihan paduan U-Mo sebagai kandidat pada pengembangan bahan bakar reaktor riset berdasar pertimbangan antara lain: penampang lintang serapan neutron unsur Mo rendah dan berat jenisnya $>16$ $\mathrm{g} / \mathrm{cm}^{3}$ sehingga densitas uranium di dalam bahan bakar dapat ditingkatkan $>8 \mathrm{gU} / / \mathrm{cm}^{3}$. Densitas uranium yang tinggi sangat menguntungkan karena muatan $235 \mathrm{U}$ di dalam bahan bakar dapat lebih banyak sehingga umur pemakaian dapat lebih lama dan ekonomis ${ }^{[2]}$.

Struktur kristal paduan U-Mo adalah bcc, pada suhu $1280^{\circ} \mathrm{C}$ terjadi reaksi peritektik dengan fasa $\mathrm{y}$ maksimum pada komposisi $40 \%$ Mo. Pada suhu yang lebih rendah $\left(<648^{\circ} \mathrm{C}\right)$ terjadi keseimbangan reaksi eutektik antara fasa $\beta(1,4 \%$ atom Mo) menjadi $\alpha\left(0,1 \%\right.$ atom Mo) dan fasa $\delta_{2}(8 \%$ atom Mo), sedangkan keseimbangan antara fasa y $(21,5 \%$ atom $)$ dengan $\alpha(<0,1 \%$ atom $)$ dan $\delta_{2}$ terjadi pada suhu $572^{\circ} \mathrm{C}^{[3]}$.

Paduan U-Mo dengan kandungan Mo antara $7 \sim 10 \%$ berat memiliki prospek yang sangat baik untuk digunakan sebagai bahan bakar nuklir dispersi dengan pengayaan uranium rendah ${ }^{[4]}$. Sebagai bahan bakar nuklir dispersi, maka paduan U-Mo yang berbentuk padat dan ulet harus diubah kedalam bentuk serbuk hingga diameter $(\varnothing)$ partikel serbuk $<150 \mu \mathrm{m}$. Sifat ulet paduan U- Mo menyebabkan proses pembuatan serbuk sulit dilakukan dengan cara mekanik, sehingga hal ini merupakan suatu tantangan dan perlu pemilihan teknik yang tepat.

Metode proses pembuatan serbuk material yang bersifat ulet seperti U-Mo dapat dilakukan dengan beberapa cara 
diantaranya: mechanical crushing (milling, grinding atau penambahan unsur pemadu untuk menambah kerapuhan, cryogenic mechanical crushing, hydride-dehydride dan proses atomisasi[5]. Proses produksi serbuk U-Mo adalah dengan membuat dekomposisi partial fasa $\mathrm{y}-\mathrm{U}$ di dalam struktur selular. Struktur ini terdiri dari fasa $\alpha-U$ dan fasa $\mathrm{y}-\mathrm{U}$ diperkaya dengan Mo atau $\mathrm{U}_{2} \mathrm{Mo}$, dimana $\mathrm{U}_{2} \mathrm{Mo}$ mula-mula berada pada batas butir (grain boundary) fasa $\mathrm{y}-\mathrm{U}$ kemudian akan tumbuh melalui pusat butir. Paduan hasil leburan dikondisikan dengan cara annealing sehingga diperoleh paduan U-Mo berstruktur selular.

Material berstruktur selular ini kemudian direaksikan dengan hidrogen menggunakan alat hidriding, maka fasa $\alpha-U$ ditransformasi menjadi $\mathrm{UH}_{3}$ yang terletak di batas butir sehingga bahan mudah pecah dan terburai menjadi bongkahan-bongkahan antar butir.

Material $U$ mudah bereaksi dengan gas $\mathrm{H}_{2}$ di sepanjang jalur suhu, namun hanya dalam bentuk fasa $\alpha$, tidak demikian halnya ketika berada pada fasa y. Reaksi U / aU dapat bereaksi dengan gas $\mathrm{H}_{2}$ seperti ditunjukkan dalam persamaan reaksi 1 .

$2 \alpha-U(s)+3 \mathrm{H}_{2}(\mathrm{~g}) \rightarrow 2 \alpha-\mathrm{UH}_{3}(\mathrm{~s})$

atau dalam bentuk paduan,

$2 \alpha-U M o(s)+x H_{2}(g) \rightarrow 2 \alpha-U_{M o H}(s)$

Logam $U$ yang semula berada pada fasa y akan mudah didekomposisi ke dalam bentuk a seperti ditunjukkan dalam persamaan reaksi 3.

$\mathrm{Y}-\mathrm{U} \quad \rightarrow \quad \alpha-U$

Kedua reaksi/ perubahan (persamaan reaksi 1 dan 2) menyebabkan komposisi U-Mo yang berada di batas butir mudah terburai menjadi bongkahanbongkahan UMo ketika bereaksi dengan gas $\mathrm{H}_{2}{ }^{[6]}$.

Melalui proses dehidriding maka fasa $\mathrm{Y}-\mathrm{U}$ akan diperoleh kembali dengan proses termal, yaitu mengatur suhu proses pada fasa $\mathrm{y}^{[7]}$. Paduan U-Mo yang diperoleh dalam bentuk butiran kasar kemudian digerus menjadi serbuk halus dengan diameter ukuran partikel $<150 \mu \mathrm{m}$. Serbuk U-Mo yang telah memenuhi persyaratan tersebut dapat dilanjutkan untuk penelitian pembuatan bahan bakar dispersi tipe pelat.

Bahan bakar dispersi tipe pelat mempunyai karakteristik yang berbeda bila dibandingkan dengan bahan bakar logam. Bahan bakar dispersi dibuat dengan teknik metalurgi serbuk sedangkan pembentukan pelat elemen bakar/ PEB dilakukan dengan pengerolan panas dan dingin.

\section{METODOLOGI}

Penelitian menggunakan bahan baku uranium (U) deplesi dan logam Mo sebagai pemadu. Logam $U$ dianalis kadar $U$ dan impuritasnya, sedangkan logam Mo dianalisis unsur-unsur logam penyusunnya. Kadar $U$ digunakan sebagai dasar perhitungan penentuan komposisi berat $U$ dan Mo yang harus ditimbang dalam pembuatan paduan U-7Mo. Komposisi berat $U$ dan Mo dilebur menggunakan tungku busur listrik dengan arus $150 \mathrm{~A}$. Peleburan dilakukan di dalam ruang tungku peleburan bermedia gas argon dan setiap paduan dilakukan peleburan dengan 5 kali pengulangan agar diperoleh paduan yang homogen. Ingot paduan U-7Mo hasil peleburan dibuat serbuk melalui dua cara yaitu secara mekanik/dikikir dan hydride dehydride - grinding mill. Proses hydride paduan U-Mo dilakukan di dalam reaktor gelas (media $\mathrm{H}_{2}$ tekanan 1,1 bar) pada temperatur $350^{\circ} \mathrm{C}$ beberapa jam dan dinginkan hingga temperatur ruangan membentuk U-7MoHx. Hidrogen yang terikat dalam bentuk paduan U-7MoHx dipanaskan pada temperatur $500^{\circ} \mathrm{C}$ hingga semua hidrogen terlepas dan U-7Mo masih tetap rapuh, dilanjutkan pembuatan serbuk dengan grinding mill di dalam glove box bermedia gas Ar. Serbuk U-7Mo dianalisis/diuji kadar U dan impuritas, berat jenis untuk perhitungan 
pembuatan komposisi berat U-7Mo dan serbuk matriks Al untuk pembuatan inti elemen bakar/IEB U-7Mo/Al densitas uranium $7 \mathrm{gU} / \mathrm{cm}^{3}$. Campuran serbuk U-7Mo dan matrik $\mathrm{Al}$ dengan perbandingan berat sesuai hasil hitung, dibentuk menjadi IEB $\mathrm{U}$ - 7Mo/Al (dimensi $25 \times 15 \times 3,15^{ \pm 0,05} \mathrm{~mm}$ ) dengan pengepresan pada tekanan 20 bar. Sebagai kelongsong dipakai pelat AIMg2 dalam bentuk frame dan 2 lembar cover. Frame berukuran $180 \times 145 \times 3,15 \mathrm{~mm}$ di bagian tengahnya dibuat lubang berukuran $25 \times 15 \times 3,15^{ \pm 0,05} \mathrm{~mm}$, sedangkan 2 cover masing-masing berukuran $180 \times 145 \times 2,7$ $\mathrm{mm}$. Selanjutnya IEB U-7Mo/Al dimasukkan ke dalam lubang frame dan kedua permukaannya di tutup dengan cover dan diikat beberapa titik pada keempat sisi sambungannya dengan las TIG menjadi paket rol. Pembentukan PEB U-7Mo/Al dilakukan dengan cara pengerolan panas paket rol (tebal: $8,55 \mathrm{~mm}$ ) pada temperatur $425^{\circ} \mathrm{C}$ dengan empat tahap hingga menjadi tebal sekitar $1,65 \mathrm{~mm}$, dan selanjutnya dilakukan pengerolan dingin hingga ketebalan $1,3^{ \pm 0,07} \mathrm{~mm}$. Setelah pemotongan dilakukan pengamatan secara visual dan pengujian tebal kelongsong ${ }^{[8]}$.

\section{HASIL DAN PEMBAHASAN}

Pembahasan penelitian meliputi paduan U-7Mo hasil proses peleburan, serbuk U-7Mo hasil proses mekanik dan hydride - dehydride - grinding mill, IEB U- 7Mo/Al dan PEB U-7Mo/Al.

\section{a. Paduan U-7Mo}

Pengamatan secara visual paduan U-7Mo hasil proses peleburan menggunakan tungku busur listrik dengan arus listrik $150 \mathrm{~A}$, dalam media gas argon diperoleh paduan cukup masif, tidak terdapat retakan dan pada permukaan paduan tidak teramati lapisan oksida uranium. Paduan U-Mo memiliki kekerasan yang cukup tinggi dan kekerasan meningkat seiring kenaikan kadar Mo. Kenaikan kekerasan kemungkinan disebabkan butiran semakin kecil dan batas butir yang semakin banyak. Mikrostruktur paduan U-7Mo hasil peleburan ditunjukkan pada Gambar 1.

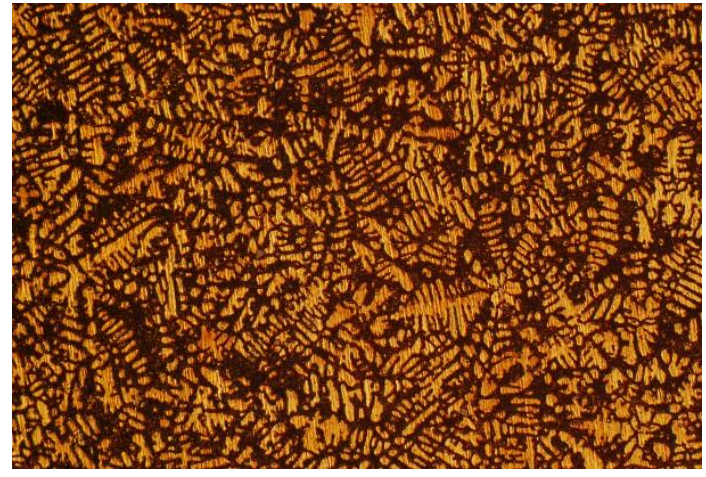

Gambar 1. Mikrostruktur paduan U-7Mo hasil proses peleburan

\section{b. Serbuk hasil proses kikir dan hydride - dehydride - grinding mill}

Ingot paduan U-7Mo cukup keras namun sangat ulet sehingga sulit diubah langsung menjadi serbuk secara mekanik seperti grinding mill. Dalam percobaan ini pembuatan serbuk dilakukan dengan menggunakan dua metode yaitu dengan cara mekanik (dikikir) dan hydride - dehydride grinding mill. Pembuatan serbuk dengan cara dikikir dilakukan di dalam glove box bermedia gas argon, sedangkan proses hydride dehydride - grinding mill menggunakan perangkat alat yang didesain untuk pembuatan serbuk dari logam/paduan logam.

Proses hidriding- dehidriding dilakukan dengan mereaksikan paduan U- 7Mo dengan gas hidrogen di dalam reaktor yang terbuat dari gelas. Paduan U- 7Mo di dalam reaktor dipanaskan pada temperatur $350^{\circ} \mathrm{C}$ dan divakum hingga tekanan 0,001 mbar. Setelah tingkat kevakuman dan temperatur dicapai, reaktor dan sistem pemipaannya diflushing dengan gas argon agar tidak ada udara yang tertinggal di dalamnya, kemudian gas hidrogen dimasukkan secara perlahan hingga mencapai tekanan sekitar 1100 mbar. Pada kondisi tersebut terjadi reaksi antara U- 7 Mo dan gas hidrogen membentuk $\mathrm{U}-7 \mathrm{MoHx}$ sehingga tekanan menurun. 
Apabila tekanan di dalam reaktor stabil dan tidak ada perubahan tekanan, hal ini mengindikasikan bahwa reaksi berhenti. Selanjutnya temperatur diturunkan perlahan dan dibiarkan selama waktu tertentu hingga terjadi reaksi antara gas hidrogen dengan paduan U-7Mo. Proses selanjutnya dilakukan dengan cara yang sama hingga temperatur ruangan sehingga seluruh paduan U-7Mo membentuk U-7MoHx yang rapuh. Pada permukaan paduan teramati retakan-retakan yang menunjukkan adanya penyerapan gas hidrogen dan telah terjadi reaksi antara gas hidrogen dengan logam tersebut. Retakan cenderung menjalar sepanjang batas butir. Paduan $\mathrm{U}-7 \mathrm{MoHx}$ sangat rapuh, namun sangat reaktif terhadap oksigen, oleh karena itu sebelum dibuat serbuk secara mekanik terlebih dahulu dilakukan proses dehidriding. Dehidriding dilakukan dengan pemanasan $\mathrm{U}-7 \mathrm{MoHx}$ di dalam reaktor pada temperatur $500^{\circ} \mathrm{C}$ selama 5 jam sehingga terdisosiasi menjadi gas hidrogen dan U-7Mo yang tetap rapuh. Paduan U-7Mo yang rapuh dibuat serbuk di dalam glove box bermedia gas argon hingga diperoleh fraksi partikel butir $<150 \mu \mathrm{m}$. Serbuk U-7Mo hasil proses dengan dikikir dan hydride - dehydride - grinding mill seperti ditunjukkan pada Gambar 2. Serbuk hasil kikir (Gambar 2.a) berbentuk pipih, sedangkan hasil proses hydride - dehydride grinding mill (Gambar 2.b) cenderung equaksial.

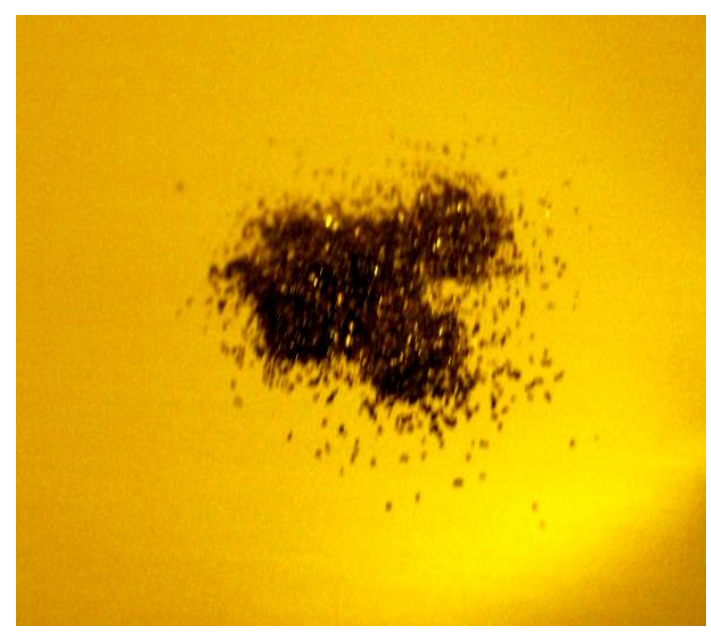

(a)

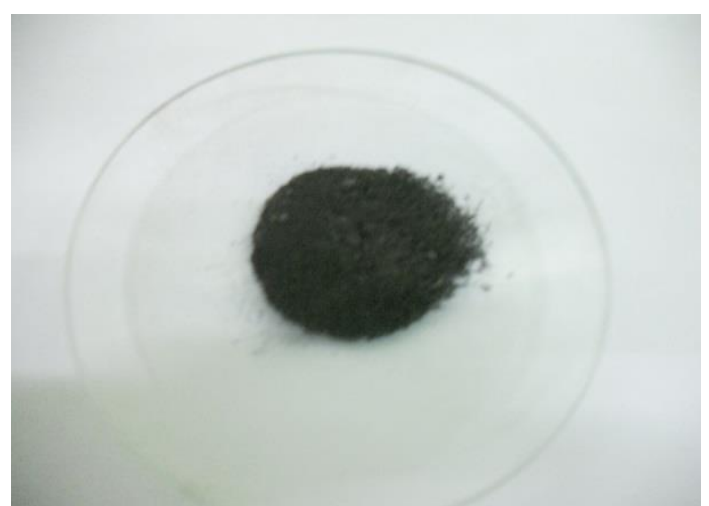

(b)

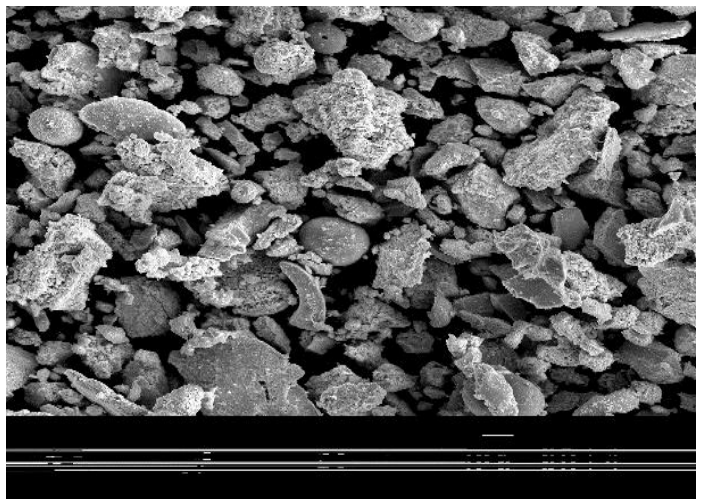

(c)

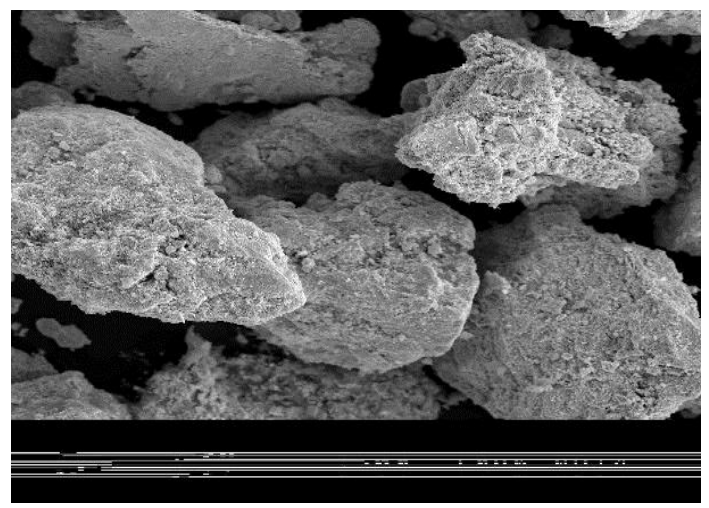

(d)

Gambar 2. Serbuk U-7Mo.
(a) hasil kikir,
(b) hasil hydride - dehydride - grinding mill,
(c) pengamatan mikroskop optik,
(d) pengamatan menggunakan SEM

Bentuk dan ukuran serbuk U-7Mo hasil proses hydride - dehydride - grinding mill yang diamati menggunakan SEM pada Gambar 2.c terlihat tidak seragam. Sebagian besar serbuk memiliki bentuk cenderung equaksial, meskipun beberapa serbuk yang lainnya ditemukan mempunyai bentuk 
accicular dan flake. Ukuran partikel sangat bervariasi dari ukuran halus hingga relatif besar, namun demikian karena pada partikel dengan ukuran cukup besar terlihat retakanretakan mikro sehingga dengan mudah terfragmentasi menjadi ukuran lebih kecil sesuai yang diperlukan sebagai bahan bakar.

Kapasitas panas (Cp) serbuk U-7Mo diukur menggunakan alat Differential Scanning Calorimetry (DSC) dengan rentang temperatur pengukuran dari $50-450^{\circ} \mathrm{C}$, kecepatan pemanasan $10^{\circ} \mathrm{C} /$ menit. Data uji dengan rentang pengukuran $20^{\circ} \mathrm{C}$ menunjukkan bahwa terjadi kenaikan nilai $\mathrm{Cp}$ dari 0,14 - 0,19 J/g.C ${ }^{[9]}$ seperti ditunjukkan pada Gambar 3. Pengukuran dengan kondisi yang sama, logam uranium mempunyai $\mathrm{Cp}$ antara $0,04-0,11 \mathrm{~J} / \mathrm{g} . \mathrm{C}^{[10]}$, dan logam Mo pada rentang pengukuran antara $50-450^{\circ} \mathrm{C}$ antara 0,12-0,32 J/g.C[8]. Kapasitas panas paduan U-Mo lebih tinggi dibanding $\mathrm{Cp}$ uranium murni, sehingga secara teoritis konduktivitas dapat ditingkatkan lebih tinggi daripada uranium murni.

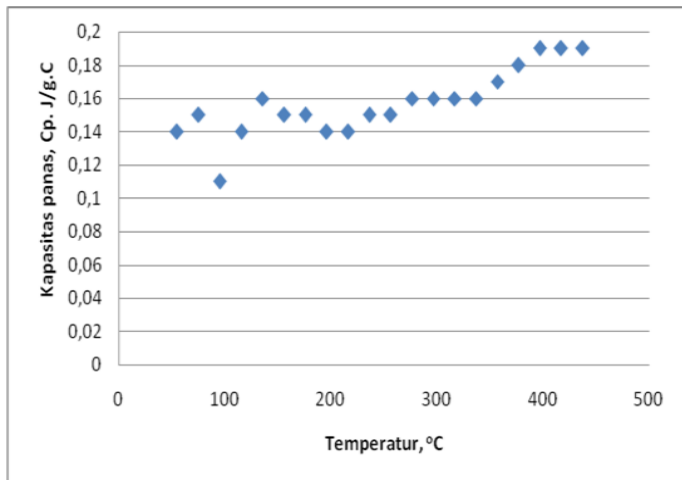

Gambar 3. Kapasitas panas serbuk U-7Mo

\section{c. Inti Elemen Bakar U-7Mo/AI}

Perbandingan berat serbuk U-7Mo dan matriks Al pada pembuatan IEB $\mathrm{U}$ - $7 \mathrm{Mo} / \mathrm{Al}$ densitas uranium $7 \mathrm{gU} / \mathrm{cm}^{3}$ dengan volume desain $25 \times 15 \times 3,15^{ \pm 0,07} \mathrm{~mm}$ adalah $8,865 \mathrm{~g} \mathrm{U}$-7Mo dan $1,469 \mathrm{~g}$ Al. Serbuk U-7Mo dan Al dihomogenisasi, kemudian dikompaksi pada tekanan 20 bar dan diperoleh IEB U-7Mo/Al seperti ditunjukkan pada Gambar 4. Pengamatan secara visual pada seluruh permukaannya, tidak teramati adanya cacat/retak. Ikatan antara serbuk U- 7Mo dan matriks Al cukup kuat sehingga tidak mudah patah. Hasil uji dengan radiografi teramati bahwa distribusi uranium di dalam IEB cukup homogen dan tidak teramati adanya aglomerasi, karena sebagai persyaratan tidak diizinkan adanya pengelompokan uranium berdiameter $\geq 1$ $\mathrm{mm}$. Dimensi IEB U-7Mo/AI hasil kompaksi sesuai desain yaitu $25 \times 15 \times 3,15^{ \pm 0,07} \mathrm{~mm}$. Panjang dan lebar IEB selalu sama dengan yang diprediksi, sedangkan ketebalan yang perlu diperhatikan karena sangat tergantung dari data masukan pada perhitungan penentuan komposisi berat serbuk U-7Mo dan Al. Parameter yang berpengaruh ketebalan adalah, kadar $U$ di dalam serbuk $\mathrm{U}$ - 7Mo, berat jenis U-7Mo dan Al, asumsi prosen pori didalam IEB dan tekanan kompaksi. Kedua sisi ujung IEB berbentuk tirus, hal ini dimaksudkan agar pada proses pengerolan PEB terjadi aliran material campuran U-7Mo dan matrik Al mengisi pada daerah tirus tersebut sehingga tidak keluar dari zona bahan bakar.

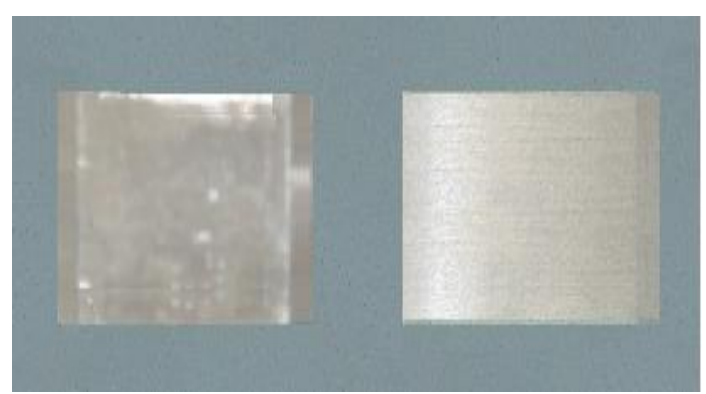

(a)

(b)

Gambar 4. Inti Elemen Bakar U-7Mo/Al menggunakan serbuk U-7Mo.

(a) hasil kikir,

(b) hasil proses hydride - dehydride - grinding mill

\section{d. Pelat elemen Bakar U-7Mo/AI}

IEB U-7Mo/Al dimasukkan ke dalam lubang frame dan kedua sisinya ditutup dengan cover AIMg2 menjadi komposit yang keempat sisi sambungannya diikat dengan las TIG beberapa titik pada keempat sambungannya. Rakitan ditipiskan dengan 
pengerolan panas pada temperatur $425^{\circ} \mathrm{C}$ hingga terjadi penipisan dari ketebalan 8,55 $\mathrm{mm}$ menjadi $1,65 \mathrm{~mm}$. Pelat hasil pengerolan panas dianil pada temperatur $425^{\circ} \mathrm{C}$ selama 1 jam, untuk uji blister/lepuhan. Hasil pengamatan secara visual di sekitar daerah meat $\mathrm{U}-7 \mathrm{Mo} / \mathrm{Al}$, tidak teramati adanya blister. Hal ini menunjukkan bahwa ikatan antara meat $\mathrm{U}-7 \mathrm{Mo} / \mathrm{Al}$ dan kelongsong AlMg2 cukup baik dan tidak terdapat udara yang terjebak di dalamnya. Hasil pengerolan PEB U-7Mo/AI (menggunakan serbuk U-7Mo hasil kikir) dari ketebalan paket rol $8,55 \mathrm{~mm}$ menjadi 1,3 $3^{ \pm 0,07}$ $\mathrm{mm}$ terjadi pemanjangan IEB dari $25 \mathrm{~mm}$ menjadi $150 \mathrm{~mm}$ (hampir $6 \times$ nya). Radiografi PEB U-7Mo/Al yang ditunjukkan pada Gambar 5, terlihat bahwa distribusi uranium cukup homogen dengan ujung meat yang cukup rata.

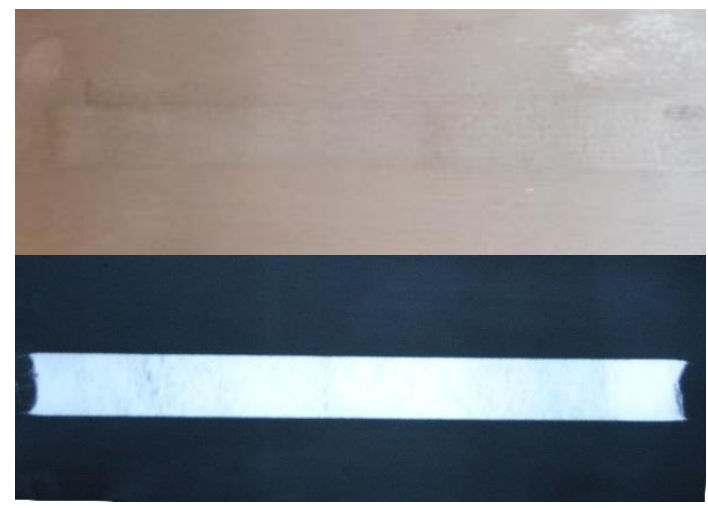

Gambar 5. Radiografi PEB U-7Mo/AI menggunakan serbuk U-7Mo hasil kikir.

Uji ketebalan kelongsong dilakukan dengan memotong bagian tengah PEB U$7 \mathrm{Mo} / \mathrm{Al}$ tegak lurus arah rol dan kedua ujungnya searah dengan pengerolan, kemudian dimounting, dipoles hingga rata kemudian difoto dan diukur tebal kelongsong dan meat pada setiap $1 \mathrm{~mm}$ sepanjang sampel menggunakan mikroskop yang dilengkapi fasilitas ukur. Foto irisan PEB U- 7Mo/Al pada Gambar 6 terlihat bahwa distribusi bahan bakar U-7Mo di dalam meat cukup homogen yang dikelilingi serbuk matriks Al. Secara teoritis di dalam bahan bakar dispersi setiap partikel bahan bakar dikelilingi oleh serbuk matriks $\mathrm{Al}$, namun hal ini sulit dicapai. Matriks Al berfungsi sebagai pengungkung produk fisi dalam bentuk gas atau padat (saat digunakan sebagai bahan bakar di dalam reaktor) sehingga memperkecil swelling PEB. Pada Gambar 6 terlihat bahwa meat bahan bakar sepanjang PEB memiliki ketebalan yang tidak sama, dan terlihat bahwa salah satu ujung terbentuk dog-bone dan ujung yang lain terbentuk whisker sedang yang tengah memiliki ketebalan yang relatif sama. Terbentuknya dog-bone disebabkan perbedaan berat jenis $\mathrm{U}-7$ Mo dan Al yang cukup jauh yaitu masingmasing 16,34 $\mathrm{g} / \mathrm{cm}^{3}$ dan 2,70 $\mathrm{g} / \mathrm{cm}^{3}$, sehingga pada proses pengerolan material U-7Mo cenderung terdorong dan terakumulasi diujung PEB membentuk dogbone yang berakibat kelongsong menjadi tipis. Hal ini terbukti dari hasil pengukuran tebal kelongsong dan meat PEB U-7Mo/Al (menggunakan serbuk U-7Mo hasil kikir) yang dilakukan setiap jarak $1 \mathrm{~mm}$ ditunjukkan pada Gambar 6 dan Tabel 1. Data uji ketebalan menunjukkan bahwa PEB $\mathrm{U}$ - 7Mo/Al dengan ketebalan $1,45 \mathrm{~mm}$ memiliki ketebalan meat rerata $0,63 \mathrm{~mm}$, dan ketebalan kelongsong rerata $0,42 \mathrm{~mm}$ dengan ketebalan kelongsong minimum 0,30 $\mathrm{mm}$ terdapat dikedua ujung PEB.

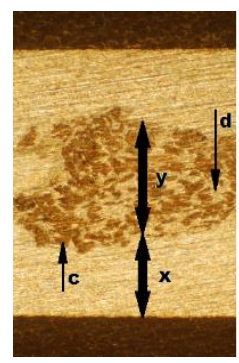

(a)

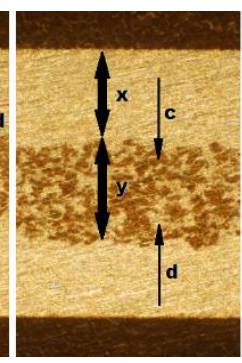

(b)

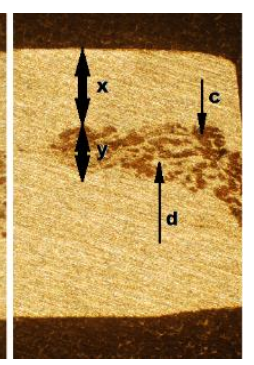

(c)
Gambar 6. Irisan PEB U-7Mo/AI, densitas Uranium $\quad 7,0 \quad \mathrm{gU} / \mathrm{cm}^{3}$ menggunakan serbuk hasil proses dikikir.

(a) Sisi Dekat

(b) Tengah,

(c) Sisi Jauh

$\mathrm{x}=$ tebal kelongsong,

$y=$ tebal meat,

$\mathrm{c}=\mathrm{U}-7 \mathrm{Mo}, \mathrm{d}=$ matriks $\mathrm{Al}$ 
Tabel 2. Data uji tebal kelongsong dan meat PEB UMo-Al densitas uranium $7 \mathrm{gU} / \mathrm{cm}^{3}$, ketebalan PEB 1,45 mm (serbuk U-7Mo hasil proses hydride - dehydride - grinding mill).

\begin{tabular}{|c|c|c|}
\hline Sisi Jauh & Tengah & Sisi Dekat \\
\hline $\begin{array}{c}\text { Ketebalan kelongsong } \\
\text { rerata, mm }\end{array}$ & $\begin{array}{c}\text { Ketebalan kelongsong } \\
\text { rerata, } \mathrm{mm}\end{array}$ & $\begin{array}{l}\text { Ketebalan kelongsong } \\
\text { rerata, } \mathrm{mm}\end{array}$ \\
\hline bag. atas bag. bawah & bag. atas bag. bawah & bag. atas bag. bawah \\
\hline 0,40 & 0,39 & 0,38 \\
\hline 0,40 & 0,41 & 0,41 \\
\hline $\begin{array}{l}\text { Ketebalan Tebal min. } \\
\text { min. }\end{array}$ & $\begin{array}{l}\text { Ketebalan Ketebalan min. } \\
\text { min. }\end{array}$ & $\begin{array}{cc}\begin{array}{c}\text { Ketebalan } \\
\text { min. }\end{array} & \text { Ketebalan } \\
\text { min. }\end{array}$ \\
\hline 0,28 & 0,37 & 0,15 \\
\hline \multicolumn{3}{|c|}{ Meat } \\
\hline Ketebalan meat rerata, $\mathrm{mm}$ & Ketebalan meat rerata, $\mathrm{mm}$ & Ketebalan meat rerata, $\mathrm{mm}$ \\
\hline 0,64 & 0,62 & 0,62 \\
\hline
\end{tabular}

\section{SIMPULAN}

Paduan U-7Mo hasil proses peleburan sangat ulet sehingga sulit diubah langsung menjadi serbuk secara mekanik. Serbuk U-7Mo hasil proses kikir berbentuk pipih, sedangkan hasil proses hydride dehydride - grinding mill cenderung equaksial. Kedua jenis serbuk U-7Mo tersebut digunakan sebagai bahan baku pembuatan IEB. U-7Mo/Al dan PEB $\mathrm{U}-7 \mathrm{Mo} / \mathrm{Al}$ diperoleh produk dengan kualitas yang hampir sama.

Membandingkan data uji PEB $\mathrm{U}-7 \mathrm{Mo} / \mathrm{Al}$ dengan jenis serbuk U-7Mo yang dibuat dengan metode yang berbeda, tidak terdapat perbedaan kualitas yang signifikan. Berdasar data penelitian yang meliputi data proses dan ujian alisis menunjukkan bahwa penggunaan serbuk yang dibuat dengan teknik hydride - dehydride - grinding mill lebih disarankan karena prosesnya sederhana, mudah dilakukan dan impuritas di dalam serbuk U-7Mo dapat diminimalkan.

\section{UCAPAN TERIMA KASIH}

Ucapan terima kasih disampaikan kepada pegawai PTBBN - BATAN yang telah membantu pelaksanaan penelitian hingga tersusunnya makalah ini.

\section{DAFTAR PUSTAKA}

[1] Ki Hwan Kim. et. al, (1996), "Development of High Loading Alloy Fuel by Centrifugal Atomization", RERTR, Korea.

[2] L. Olivares, et. al, (2010) "Microstructural Characterization of Dispersion Fuel Miniplates Made Of Hydrided U+7wt\%Mo Powder," International Meeting on RERTR, Lisabon.

[3] Ivanov et. al, (1983), "Phase Diagram of Uranium alloys", Amerind Publishing Co PVT.LTD, New Delhi.

[4] Solonin, M.I, et. al, (2000), "Development of the Method of High Density Fuel Comminution by HydrideDehydride Processing", International Meeting on RERTR, Las Vegas.

[5] Fabio Branco, et. al, (2007) "Powder Formation of $y$-Uranium-Molybdenum Alloys via Hydration-Dehydration", $29^{\text {nd }}$ International Meeting on RERTR, Prague.

[6] Oliveira, F.B.V. et. al, (2007), "Methods For Fabricating Gamma - Uranium Molybdenum ( $y$-UMo) Alloys and Their Influence on Powder Obtention by the HDH Technique", submitted to the European Nuclear Conference ENC, September, Brussel. 
[7] Fabio Branco, (2014), "Relation Between Gamma Decomposition and Powder Formation of $\mathrm{y}$-U8Mo Nuclear Fuel alloys via Hydrogen Embrittlement and Thermal Shock", World Journal of Nuclear Science and Technology, 4, 177 $-188$.

[8] Supardjo. et. al, (2012), "Pengaruh Fabrikasi Pelat Elemen Bakar U-7Mo/AI Dengan Variasi Densitas Uranium Terhadap Pembentukan Pori di Dalam Meat dan Tebal Kelongsong", Jurnal Teknologi Bahan Nuklir, Vol. 8 No 2.

[9] Supardjo. et. al, (2013), "Karakterisasi Ingot Paduan U-7Mo-xTi Hasil Proses Peleburan Menggunakan Tungku Busur Listrik", Jurnal Teknologi Bahan Nuklir, Vol. 9, no.2.

[10] Aslina, Br. Ginting. et. al, (2007), "Pengaruh Temperatur Terhadap Sifat Termal Paduan U-Zr dengan Variasi Kandungan Zr", Buletin Triwulan Daur Bahan Bakar Nuklir, URANIA, Vol. 13 No. 3.
[11] A. Soba, A. Denis, (2007), "An Interdiffusional Model for Prediction of the Interaction Layer Growth in the System Uranium-MolybdenumAluminium" Journal of Nuclear Materials.

[12] E. Perez, Y.H, Sohn, D.D.Keiser, (2008), "U-Mo/Al Alloys Diffusion Couples FuelCladding Interactions", NIST Diffusion Workshop, May 12, 2008, Idaho National Laboratory, University of Central Florida.

[13] J. Allenou, O. Tougait, M. Pasturel, X. Iltis, F. Charollais, M.C. Anselmet, P.Lemoine, (2011), "Interdiffusion Behaviors in Doped Molybdenum Uranium and Aluminium or Aluminium Siliocon Dispersion Fuel : Effects of the Microstructure", Journal of Nuclear Materials. 